\title{
Solar belt supplies electricity for the World
}

\author{
Dr. Péter Kádár, senior member of IEEE \\ Óbuda University \\ Dept. of Power Systems, Alternative Energy Sources Knowledge Centre \\ Bécsi u. 94. Budapest H-1034 HUNGARY \\ Phone: +36 209447 241; fax: +30 1250 0940; e-mail: kadar.peter@kvk.uni-obuda.hu
}

\begin{abstract}
The major part of the electricity production is generated on fossil base. The renewable generation emits far less $\mathrm{CO}_{2}$. In this paper we investigate a vision how all the electricity need could be supplied by solar PV plants

Our technical vision is a solar belt surrounding the earth near the equator. If we calculate the power capacities a narrow stripe could produce all the electricity need for the whole World. At first sight we do not store the energy but try to produce it on the sunny side and transmit to the dark side 'on-line' the necessary amount. We plan for this long distance/high energy transmission UHVDC network.

We made a bulk calculation about the availability of this approach and we find on-line PV supply of the World technologically feasible. If we don't have a "green field investment" only with PV solution but we start from the existing situation and we build more PV and we create a large East-West transmission system, it can alleviate the present energy problems.
\end{abstract}

\section{Key words}

Worldwide electricity demand, supply only with Photovoltaic generation, UHVDC lines

\section{Introduction}

Nowadays dozens of electrical energy generation tools are known, such as fossil, nuclear and renewables. The nearly unlimited solar power sources of the deserts inspire mankind to explore that for electrical supply $[1,2,3]$. The solar technologies change the power and transportation industry as well [5]. The efficiency of PV technologies emerges continuously $[6,7,8]$.

In this paper we imagine how we could supply the World by purely renewable photovoltaic sources. The basic idea is a global PV belt around the globe that always has an irradiated part, meanwhile the other side is in the shadow. The surplus from the belighted side should be transported to the dark side. It is important to mention that we plan with (nearly) existing technologies.

\footnotetext{
${ }^{1}$ https://en.wikipedia.org/wiki/Electricity_sector_of_ the_United_States

${ }^{2} \mathrm{https} / / /$ en.wikipedia.org/wiki/Electricity_sector_in_China

${ }^{3} \mathrm{https} / / / \mathrm{www}$. entsoe.eu/Documents/Publications/ Statistics/YSAR/141515_YSAR_2013 report.pdf

${ }^{4}$ https://www.entsoe.eu/Documents/Publications/

Statistics/electricity_in_europe/entsoe_
}

\section{A. Assumption of the demand}

First we make a rough estimation of the electricity consumption of the World. Based on the facts we make an assumption for the next 10 years. The yearly electrical energy consumption is clear but the World's peak consumption isn't. A country has a well-known and schedulable peak load. The peaks in the different countries aren't synchronized due to the rotation of the globe, so there is a peak shift. The peak hours are typically at 5-6 PM in each country. For the illustration of the electrical energy need we show some data (Table I. and II.).

Table I. Built in capacities and yearly energy demands

\begin{tabular}{|l|l|}
\hline Built Capacity in the USA 2014 & $1064 \mathrm{GW}^{1}=1.064 \mathrm{TW}$ \\
\hline Generating Capacity China 2014 & $1505 \mathrm{GW}^{2}=1.505 \mathrm{TW}$ \\
\hline Generating Capacity Europe 2013 & $992 \mathrm{GW}^{3}=0.992 \mathrm{TW}$ \\
\hline $\begin{array}{l}\text { Electricity Consumption Peak, } \\
\text { Europe 2012 }\end{array}$ & $557 \mathrm{GW}^{4}=0.557 \mathrm{TW}$ \\
\hline $\begin{array}{l}\text { Yearly Electricity Consumption of } \\
\text { the World 2008 }\end{array}$ & $20,280 \mathrm{TWh}^{5}$ \\
\hline $\begin{array}{l}\text { Yearly Electricity Consumption of } \\
\text { the World 2013 }\end{array}$ & $23,322 \mathrm{TWh}^{6}$ \\
\hline
\end{tabular}

Table II. Average installed power capacity in TW of primary energy by source ${ }^{7}$

\begin{tabular}{|l|l|l|l|}
\hline Fuel type & \multicolumn{1}{|c|}{1980} & \multicolumn{1}{|c|}{2004} & \multicolumn{1}{|c|}{2006} \\
\hline Oil & 4.38 & 5.58 & 5.74 \\
\hline Gas & 1.80 & 3.45 & 3.61 \\
\hline Coal & 2.34 & 3.87 & 4.27 \\
\hline Hydroelectric & 0.60 & 0.93 & 1.00 \\
\hline Nuclear power & 0.25 & 0.91 & 0.93 \\
\hline
\end{tabular}

electricity_in_europe_2015_web.pdf

${ }^{5}$ https://en.wikipedia.org/wiki/Electric_energy_ consumption

6 "Key World Energy Statistics 2015" www.iea.org. IEA. 2015. pp. 8, 37.

${ }^{7}$ EIA - Energy Information Administration 


\begin{tabular}{|l|l|l|l|}
\hline $\begin{array}{l}\text { Geothermal, wind, solar } \\
\text { energy, wood }\end{array}$ & 0.02 & 0.13 & 0.16 \\
\hline Total & 9.48 & 15.0 & 15.8 \\
\hline
\end{tabular}

Based on the data above we count with $5 \mathrm{TW}$ concurrent load worldwide.

\section{Physical set up}

\section{A. Used technologies}

We are witness of the radical technology development also in the transmission and PV areas: the voltage level of the HVDC step over the $1 \mathrm{MV}$ (Ultra High Voltage Direct Current transmission), the price of the PV cells is decimated in the last decade. We are going to count only with (nearly) real devices.

Let's use the existing, fixed installation PV technologies:

- Power generation density: 0,5 - $1 \mathrm{MW} / 1$ hectar $^{8}$

- $\quad$ Average area requirement $=0,8$ ha $/ \mathrm{MW}$

The Concentrated Solar Power plant - CSP is a different technology, now we don't calculate with it. Please remember the CSP has a lag in the production schedule so it works also as a storage. The solar trackers also influence the time-characteristics.

Let's use the existing HVDC transmission technologies:

- A +/- $800 \mathrm{kV} 2000 \mathrm{~km}$ HVDC line for $6000 \mathrm{MW}^{9}$ costs 2 billion USD.

- $\quad$ A 7.2 GW, 1.6 MV DC Pole-Pole 2,000 km

Transmission Line ${ }^{10}$ exists, too.

- $\quad$ Thyristors are planned for $>10 \mathrm{GW}$ Power Transmission $^{11}$

We suppose that in the near future the $50 \mathrm{GW}$ UHVDC transmission will be available.

\section{B. Radiation model}

- The solar irradiation from the Sun towards the globe is closely continuous.

- $\quad$ The diameter of the earth is $12750 \mathrm{~km}$.

- The peak power need that we must supply in the same moment around the World is closely 5TW (estimated).

- Let's put a ring-stripe around the globe at the equator. Total length is approximately $40000 \mathrm{~km}$.

- Let's have solar panels with tilt 0 (means all the panels are placed horizontally). Lengths of the continuously irradiated stripe is $20000 \mathrm{~km}$.

From the ideal surrounding stripe taking into the reality we move to the real PV fields (see Fig.1.):

$a$., continuous stripe along the equator

$b$., from the rainy equator we pull up/down two halve-stripes to the shiny desert areas.

\footnotetext{
${ }^{8} \mathrm{http}: / / \mathrm{www}$.solarmango.com/scp/area-required-for-solar-pvpower-plants/ -1 ha $=1$ hectar $=10000 \mathrm{sqm}$

$9800 \mathrm{kV}$ HVDC - big technological step - ABB; http://www04.abb.com/global/seitp/seitp202.nsf/0/5392089edc1b 3440c12572250047fd78/\$file/800+kV+DC+technology.pdf
}

c., instead of the continuous PV field we have some concentrated fields on the continents.
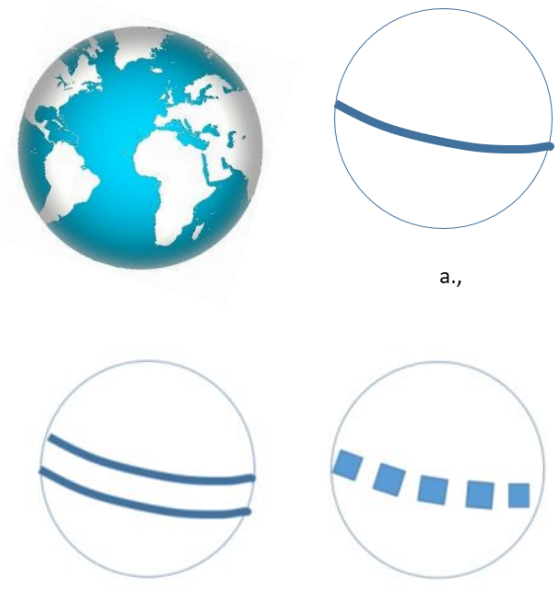

b.,

c.,

Fig. 1. Development of the PV parks deployment

The total length of the PV fields almost $40000 \mathrm{~km}$. But how long is the actually operating part? How much power is generated actually? Continuous irradiation arrives from the Sun to the rotating equator stripe. All the panels are in horizontal position (the tilt is 90 degree). The irradiation is closely maximal at noon.

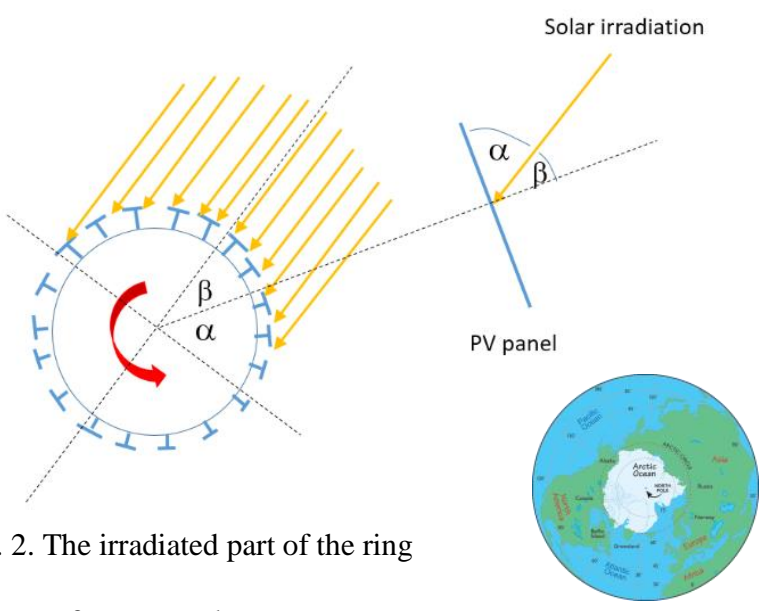

Power of one panel:

$$
\begin{aligned}
P=I_{0} * \cos \beta * A & =I_{0} * \cos \beta * W * L \\
\cos \beta & =\sin \alpha
\end{aligned}
$$

where

$$
\begin{aligned}
& \mathrm{P}=\text { power generation of one panel } \\
& \mathrm{I}_{0}=\text { global irradiation is about } 1000 \mathrm{~W} / \mathrm{m}^{2} \text { at clear } \\
& \text { sky } \\
& \alpha=\text { elevation of the arriving solar beam - related } \\
& \text { the horizon (elevation of the Sun) } \\
& \beta=\text { deviance of the solar beam from the } \\
& \text { perpendicular beam } \\
& \mathrm{A}=\text { Area of the PV panel/stripe }
\end{aligned}
$$

\footnotetext{
${ }^{10} \mathrm{http} / / / \mathrm{cr} 4$.globalspec.com/thread/59814/7-2-GW-1-6-MVDC-Pole-Pole-2-000-km-Transmission-Line

${ }^{11}$ Vobecky, Liu: Thyristors for >10 GW Power Transmission; http://new.abb.com/docs/librariesprovider109/defaultdocument-library/thyristors-for-10-gw-powertransmission_sep2014.pdf?sfvrsn=2
} 
$\mathrm{W}=$ Width of the panel/stripe

$\mathrm{L}=$ Length of the panel/stripe

We have a bended stripe covering the globe and only the half of it is irradiated. The irradiation has different angles if incidence that is why we must sum up the elemental small effective irradiations/powers - along the ring. The infinitesimally small elementary PV panel: 'dr' is equal with ' $r * d \alpha$ ' because the lengths of the perimeter is equal with the central angle measured in radian times radius.

$$
\begin{gathered}
d r=r * d \alpha \\
P_{\text {total }}=W * L * I_{0} * \int_{\alpha=0}^{\alpha=\frac{\pi}{2}} I_{0} \sin \alpha * r *(d \alpha) \\
P_{\text {total }}=W * L * I_{0} * r * 1
\end{gathered}
$$

where

$\mathrm{P}_{\text {total }}=$ power generation of the 1 quarter of the PV stripe along the equator (90 degree)

$r=$ radius of the Earth

We got that the 'useful' equivalent lengths of the ring in spite of $\pi / 2 * \mathrm{r}$ is only $2 * \mathrm{r}$. That is the diameter of the ring: in other words this is the projection of the half-ring.

Rough calculation:

- Based on the above calculation the 'Useful length' of the stripe is $12750 \mathrm{~km}$

- $\quad$ The power requirement is $5 \mathrm{TW}=5 * 10^{6} \mathrm{MW}$

- For the production of this amount of power the required $\mathrm{PV}$ area is $1,25 * 10^{6} \mathrm{ha}=1,25 * 10^{4} \mathrm{~km}^{2}$

To cover this size area width continuous belt a $1 \mathrm{~km}$ wide stripe is required (area $=1 \mathrm{~km} \times 12750 \mathrm{~km}=$ $12750 \mathrm{~km}^{2}$ )

\section{$1 \mathrm{~km}$ wide PV stripe should be enough to cover the whole electricity demand of the World!}

\section{The power network}

\section{A. Load and generation in space and time}

There is always a half-ring stripe irradiated by the Sun. The power production (in case of clear sky is always 5 TW.) We must transmit the energy to the other side of the globe too. We build a power network that can transmit the local surplus to the Northern/Southern consumption areas and also to the dark side of the globe (in the direction East and West). In the example we count with $2000 \mathrm{~km}$ wide cells. At the corner points there are the local loads and the surplus energy from the region should be transmitted to the other side of the globe.
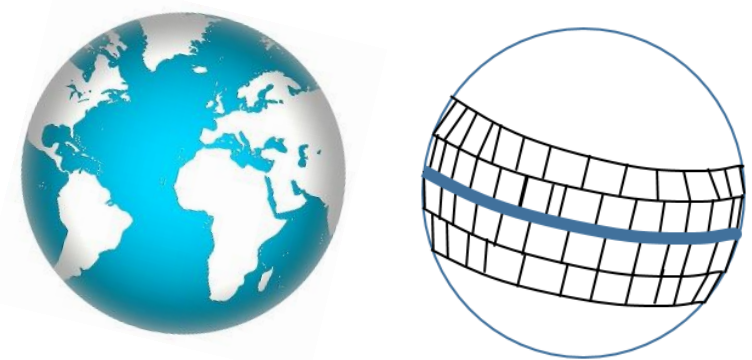

Fig. 3. HVDC network of the single stripe PV field

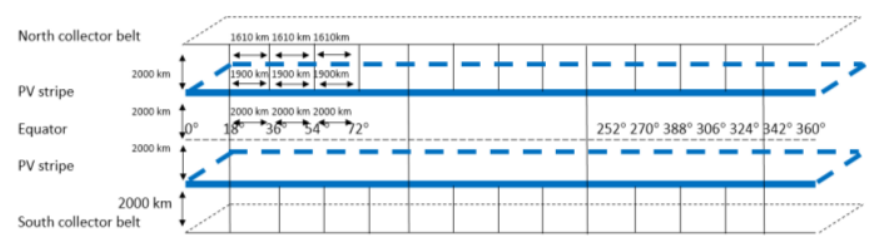

Fig. 4. Layout of HVDC network for double stripe PV fields

Each countries has definite load profile that is known and forecastable by the System Operator. In the simulation we can replace it with a constant load plus a shifted sinusoidal change. Also the peak is about $5-6$ hours after noon (5 PM - red scattered line in Fig. 5).

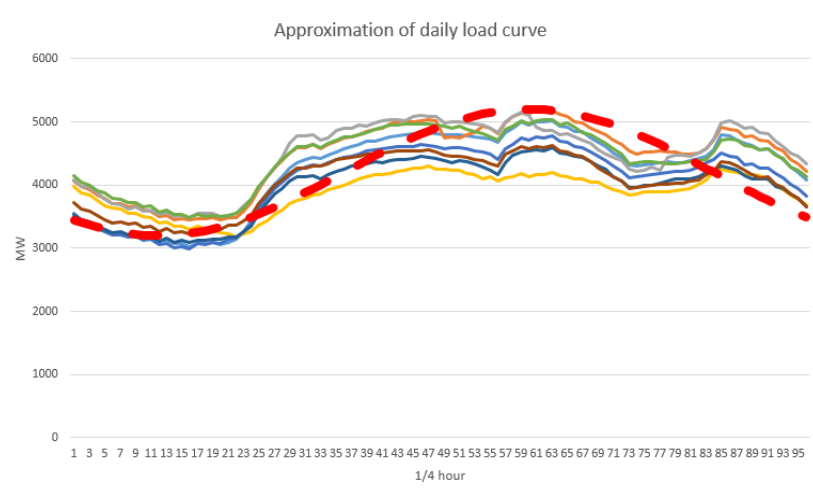

Fig. 5. A possible local daily load profile ${ }^{12}$

The PV production isn't centrally symmetric on the horizontal cross section of the globe but it has a symmetry axe from the actual noon point ( 90 degree - in Fig. 6 - the noon is actually somewhere in East-India) and to the midnight point (opposite site of the globe - 270 degree in the fig 6).The PV generation "wave" travels around the globe, daily. The axe-symmetric load curve rotates with the PV wave. The daily peak load time has 5 hours shift to the noon, the deep valley 2-3 hours after the midnight.

Boundary conditions:

- $\quad$ regarding the solar irradiation we don't take into account the seasonality and the obliquity (axial tilt) of the globe $\left(23,5^{\circ}\right)$

- first we calculate with the clear-sky model (no clouds)

In the next Figure 6 one can see the generation (grey), the load (blue) and the local surplus around the globe (orange) 
- in the 360 degree in cylindrical coordinate system. The surplus must be transmitted to the actual consumption sites. Its cumulated value is shown by yellow line.

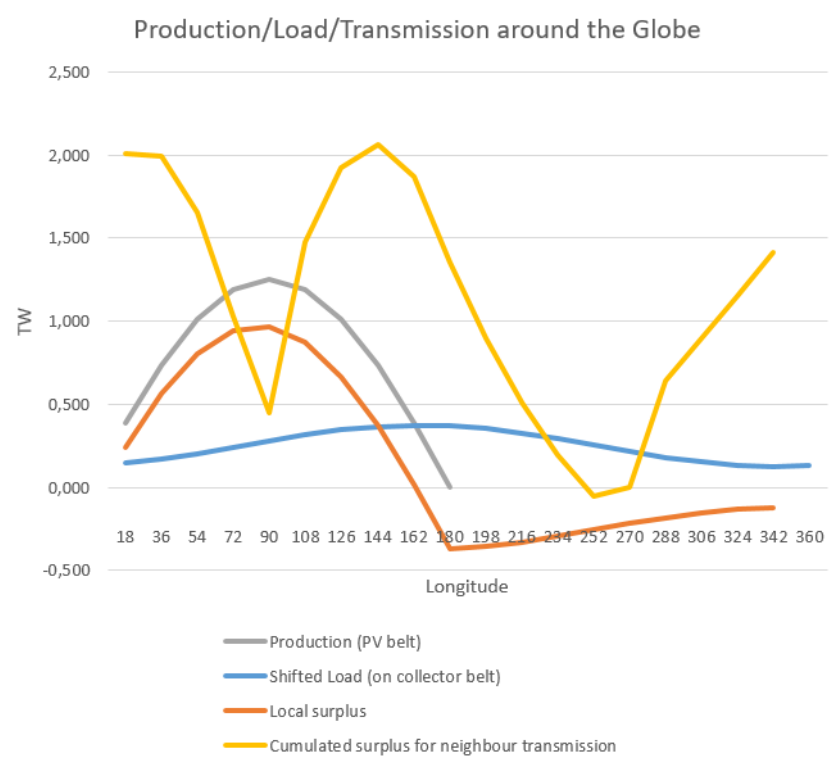

Fig. 6. The balance of the local load/production and the necessary transmitted power

\section{B. Transmission}

In the primary calculation we don't use energy storage. The total transmission/distribution loss is $1 / 3$, so for the 5,2 TW load we generate 7,9 TW Photovoltaic power. In figure 7 and table III. we can see the necessary power transmission in the direction West and East. The networks should be fault tolerant and redundant [4].

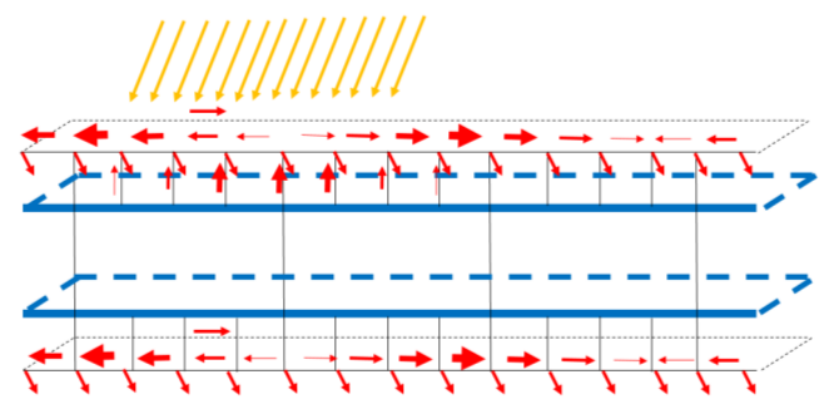

Fig. 7. Main flows from the dual belt system

\section{Network calculation}

The flows of the power system can be exactly calculated. The AC Load-Flow calculation is an iterative method that seeks the current, active and reactive flows of branches and the voltages of nodes. Also the Kirchhoff loop and node law is applied.

In the HVDC calculation the node voltage doesn't define the flows. In the line the Ohm law is valid but the flows are forced by the inverter/converter fire angle.

In the example:

\footnotetext{
- $\quad$ Total production is 7,9 TW

- $\quad$ Network loss is $33 \%$

- $\quad$ Net load is 5,25 TW
}

Table III.: Load and generation around the globe

\begin{tabular}{|c|c|c|c|c|c|c|}
\hline $\begin{array}{l}0 \\
0 \\
z \\
z \\
\vdots \\
0 \\
0 \\
z\end{array}$ & 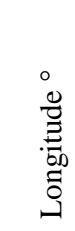 & 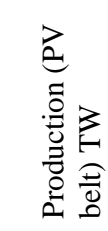 & 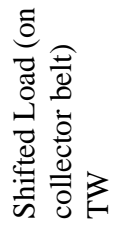 & 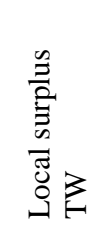 & 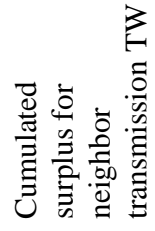 & 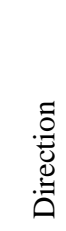 \\
\hline 1 & 0 & 0,000 & 0,129 & $-0,129$ & 1,694 & $\Delta$ \\
\hline 2 & 18 & 0,386 & 0,145 & 0,241 & 2,012 & $\Delta$ \\
\hline 3 & 36 & 0,734 & 0,171 & 0,563 & 1,994 & $\Delta$ \\
\hline 4 & 54 & 1,011 & 0,205 & 0,806 & 1,653 & $\Delta$ \\
\hline 5 & 72 & 1,189 & 0,243 & 0,945 & 1,031 & $\Delta$ \\
\hline 6 & 90 & 1,250 & 0,282 & 0,968 & 0,450 & $\nabla \Delta$ \\
\hline 7 & 108 & 1,189 & 0,318 & 0,871 & 1,475 & $\nabla$ \\
\hline 8 & 126 & 1,012 & 0,347 & 0,665 & 1,926 & $\nabla$ \\
\hline 9 & 144 & 0,736 & 0,367 & 0,369 & 2,066 & $\nabla$ \\
\hline 10 & 162 & 0,388 & 0,375 & 0,013 & 1,871 & $\nabla$ \\
\hline 11 & 180 & 0,002 & 0,371 & $-0,369$ & 1,352 & $\nabla$ \\
\hline 12 & 198 & & 0,355 & $-0,355$ & 0,898 & $\nabla$ \\
\hline 13 & 216 & & 0,329 & $-0,329$ & 0,512 & $\nabla$ \\
\hline 14 & 234 & & 0,295 & $-0,295$ & 0,195 & $\nabla$ \\
\hline 15 & 252 & & 0,257 & $-0,257$ & $-0,055$ & $\nabla$ \\
\hline 16 & 270 & & 0,218 & $-0,218$ & walley & \\
\hline 17 & 288 & & 0,182 & $-0,182$ & 0,644 & $\Delta$ \\
\hline 18 & 306 & & 0,153 & $-0,153$ & 0,898 & $\Delta$ \\
\hline 19 & 324 & & 0,133 & $-0,133$ & 1,151 & $\Delta$ \\
\hline 20 & 342 & & 0,125 & $-0,125$ & 1,412 & $\Delta$ \\
\hline & $\begin{array}{l}\text { sum } \\
\text { TW }\end{array}$ & 7,89 & 5,24 & TW & & \\
\hline
\end{tabular}

The maximum power to transmit to the neighboring cell is $2 \mathrm{TW}$. It is large, but counting with $50 \mathrm{GW}$ lines we need 20 pcs in the Southern hemisphere and 20 pcs in the Northern hemisphere. It seems to be lot but in the theoretical calculation we let it.

\section{Positioning the converters}

The basic settings of the HVDC transmission is the $\mathrm{AC} / \mathrm{DC}$ and DC/AC rectifier and inverter at the two ends.

The PV production is DC, so we need "only" $\mathrm{DC} / \mathrm{DC}$ converters or DC/AC inverter - transformer - AC/DC rectifier. This second solution can be cheaper, and we can also use higher frequency than $50 / 60 \mathrm{~Hz}$. In this case the size of the transformer can be smaller.

For the transmission of the huge power we need dozens of parallel HVDC lines. Of course at the load feeding points we need DC/AC inverters but at the connection point of DC - DC sections we do not have to change to AC. In this case instead of power electronics at both end of each lines we need less power electronics. Also some DC-DC sections can be longer than the initial $2000 \mathrm{~km}$ (see fig.8). 


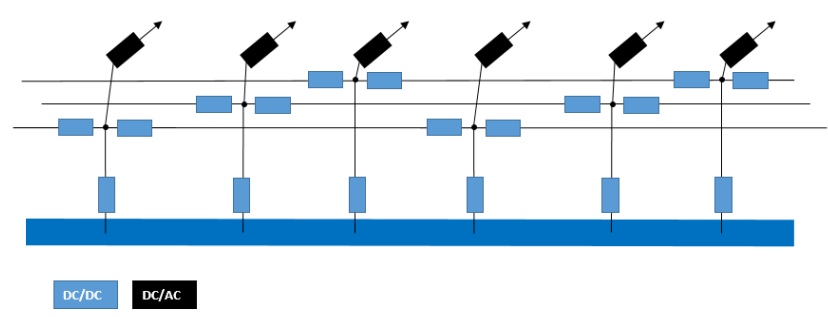

Fig. 8. A part of the DC transmission network

Finally we must take into account the reality. Although there are some floating PV applications the high power harvesting system must be placed on terrain. The need is emerging for long distance undersea HVDC cables. If we haven't continuous PV stripe the partial PV plants must be wider. But don't forget: approximately $40000 \mathrm{~km}$ long and $1 \mathrm{~km}$ wide area is enough for the energy production: it can be replaced e.g. by 400 pcs of $10 \mathrm{~km} * 10 \mathrm{~km}$ or 4 pcs of $100 \mathrm{~km} * 100 \mathrm{~km}$ areas! The fig. 9 shows a vision of some large PV plants and two DC transmission corridor around the globe.

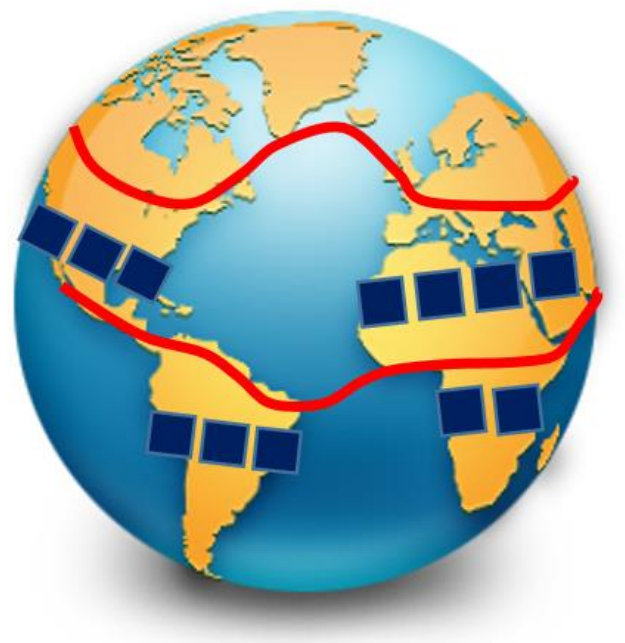

Fig. 9. Concentrated PV plants and HVDC transmission

\section{Pros and cons}

Some points that show towards the realisation such system:

- local generation can decrease the need for the central PV generation

- local storage facilities decrease the need for long distance transmission

- a smart Demand Side Management can fit the local load to the generation. In this aspect the mid-day consumption is encouraged because of "use more power when the Sun shines!" This is controversial to the traditional, paradigm: "use cheap night power instead of daily peak power!"

- the change of the traditional energy selling paradigm: from "We generate as much electricity as you want" to "use the electrical energy more efficiently and try to decrease your consumption".

On the other hand some points are against the renewable solution:
- the cloudy sky can strongly influence the PV generation

- the long distance transmission has too many losses and stability problems

- financial obstacles

- possible technical problems

- vulnerability because of local political and economic situation

For further investigation the following aspects should be studied:

- financing

- technological feasibility of construction

reserving with other sources

- $\quad$ storage instead of transmission

\section{Conclusion}

Regarding the above rough calculation the full - on-line PV supply of the World is technologically feasible.

If we don't have a "green field investment" only with PV solution but we start from the existing situation, we build more PV and we create a large East-West transmission system, it can alleviate the present energy problems.

\section{References}

[1] A. Boudghene Stambouli: Analysis of Power Generation and Transmission from Very Large-Scale Photovoltaic Systems in Algeria; International Conference on Renewable Energies and Power Quality (ICREPQ'16), At Madrid (Spain), Volume: No.14, ISSN 2172-038

[2] A. Boudghene Stambouli, S. Flazi, A. Tahri and H. Koinuma: Powering the planet with solar fuel: SSB project challenges in solar grand plan energy utilisation The 5th Asia-Arab SustainableEnergy Forum \& the 7th Int Workshop on SSB Tsukuba, Japan, May 10-13, 2015

[3] Keiichi Komoto, Ed: IEA PVPS Task8: Energy from the Desert, Very large scale PV power -state of the art and into the future; 27 th European Photovoltaic Solar Energy Conference, 24-28 September 2012, Frankfurt, Germany

[4] Judith Pálfi, Péter Holcsik, Miklós Tompa:Network Science Tools applied to Low Voltage Networks In: Szakál Anikó, Ed. 17th IEEE International Symposium on Computational Intelligence and Informatics (CINTI 2016). Budapest, Hungary, 2016.11.17-2016.11.19. (ISBN:978-1-50903908-1)

[5] Andrea Varga - Peter Kadar: PhotoVoltaic EV Charge Station; 12th International Symposium on Applied Machine Intelligence and Informatics (SAMI 2013) Herlany, Slovakia Jan.31- Feb. 2., 2013 Submission 54

[6] Fatima Zohra Zerhouni, M'hamed Houari Zerhouni, Mansour Zegrar, M. Tarik Benmessaoud, Amine Boudghene Stambouli, Abdelhamid Midoun: Proposed Methods to Increase the Output Efficiency of a Photovoltaic (PV) System; Acta Polytechnica Hungarica Vol. 7, No. 2, 2010.

[7] Péter Kádár, Tibor Kliment jr: Autoregression test of Solar Photovoltaic energy generation; 3rd IEEE International Symposium on Exploitation of Renewable Energy Sources; March 11-12, 2011; Subotica, Serbia

[8] Andrea Varga - Peter Kadar: Measurement of spectral sensitivity of PV cells; IEEE 10th International Symposium on Intelligent Systems and Informatics September 20-22, 2012; Subotica, Serbia 